\title{
ФУНКЦИОНАЛЬНАЯ МОДЕЛЬ УСТОЙЧИВОСТИ ЧЕЛОВЕКА
}

\section{FUNCTIONAL MODEL OF STABILITY OF THE PERSON}

\section{Kazankov}

Summary: In article stability of the person as process, a state and property is considered. Earlier in scientific literature such approach was not offered. Process, a state and property define functional model of stability of the person. The functional model of stability of the person is understood as stability as process, a state and property (fig. 1). Stability as process is purpose formation, decision-making, adaptation, endurance and permission. Stability as a state is readiness, activity, satisfaction and rest. Stability as property is accumulation, selectivity, plasticity, variability, steadiness and resilience. The model is one of scientific results of dissertation research of the author of article. Each element of model is briefly opened on a course of a statement of information. On the example of Gauss's curve the dynamic party of stability of the person taking into account functional model (fig. 2) is shown.

Keywords: sustainability, the psychology of sustainability, man, human biopsychosocial system, biotechnosociety, process, state, property, adaptation, readiness, endurance, resilience.
Казанков Вячеслав Владимирович

К.п.н., докторант, Санкт-Петербургский Университет Государственной противопожарной службы МЧС России; генеральный директор, ООО «Первый Легион», Санкт-Петербург legionfirst@mail.ru

Аннотация: В статье рассматривается устойчивость человека как процесс, состояние и свойство. Ранее в научной литературе такой подход не предлагался. Процесс, состояние и свойство определяют функциональную модель устойчивости человека. Под функциональной моделью устойчивости человека понимается устойчивость как процесс, состояние и свойство (рис.1). Устойчивость как процесс есть формирование цели, принятие решения, адаптация, выносливость и разрешение. Устойчивость как состояние есть готовность, активность, удовлетворенность и покой. Устойчивость как свойство есть аккумулирование, избирательность, пластичность, изменчивость, уравновешенность и сопротивляемость. Модель является одним из научных результатов диссертационного исследования автора статьи. Каждый элемент модели кратко раскрыт по ходу изложения информации. На примере кривой Гаусса показана динамическая сторона устойчивости человека с учетом функциональной модели (рис. 2).

Ключевые слова: устойчивость, психология устойчивости, человек, биопсихосоциальная система человека, биотехносоциум, процесс, состояние, свойство, адаптация, готовность, выносливость, сопротивляемость.

Мы предлагаем рассматривать функциональную модель устойчивости человека, как это проиллюстрировано на рис.1. При формулировании тех или иных понятий автор, прежде всего, опирался на источник [6].

ет рассматривать как процесс, состояние и свойство [1]. Модель должна раскрывать именно функциональную (динамическую) сторону феномена устойчивости. На функциональные особенности устойчивости обратила внимание E. Seville указав, что устойчивость определяется как динамический процесс с проявлением положительной поведенческой адаптацией [2]. По ее мнению, устойчивость есть поиск возможностей, возникающих во время кризиса чтобы выйти из него не сломленным и лучше. Такого же мнения придерживается N. Taleb при рассмотрении вопроса, связанного с антихрупкостью [3]. Е.П. Крупник и Н.В. Кисельникова отмечают, что в рамках личностного подхода выделяется категория психологической устойчивости, интерпретируемой как подвижное равновесие [4].

Под устойчивостью человека следует понимать его способность к сохранению здоровья на психофизиологическом, психологическом и психосоциальном уровнях жизнедеятельности под воздействием разрушителей [5, с.303]. Психофизиологический, психологический и психосоциальный уровни образую биопсихосоциальную систему устойчивости человека. Каждый уровень имеет свои оценочные маркеры.

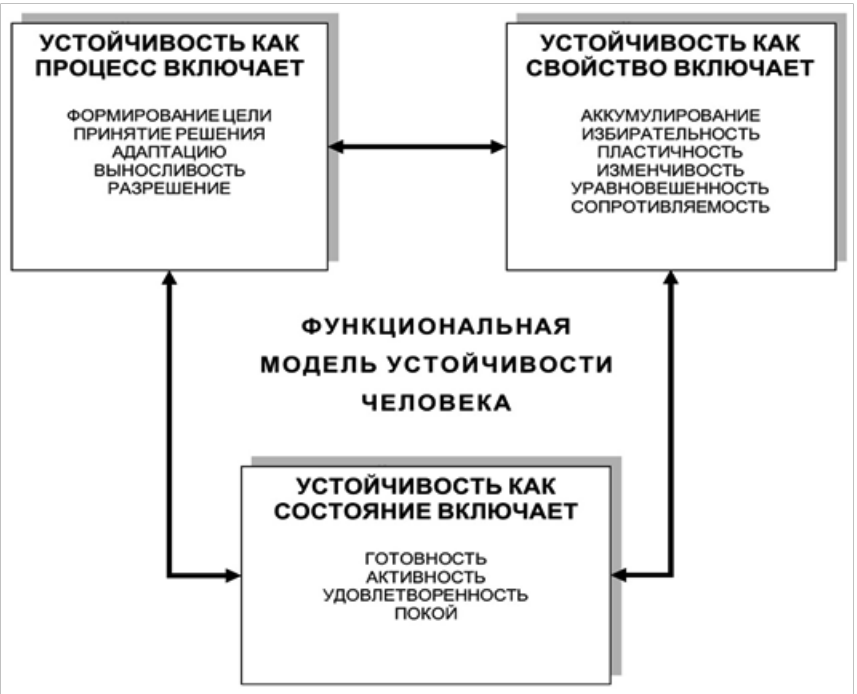

Рис.1. Функциональная модель устойчивости человека.

Устойчивость человека, как прочесс, выражена: формированием чели, принятием решения, адаптацией, выносливостью и разрешением. Любое действие чело- 
века направлено на достижение определённой цели посредством трудовой деятельности, что является неким «барометром» устойчивости человека. Устойчивость как процесс формирования цели характеризуется специфическим внутренним отношением между субъективным ее смыслом для человека и объективным ее значением для биотехносоциума. Под биотехносоциумом следует понимать мир всей природы, техники, общества.

За формированием цели следует процесс принятия решения - перехода от мысли к действию. Принятие решения заключается в выборе одного или нескольких вариантов действия для достижения поставленной цели из некоторого исходного множества альтернатив. Следует отметить, что принятие решения есть волевая система интеллектуальных и коммуникативных действий человека.

Адаптация - важный процесс устойчивости человека, характеризующий постоянную активность приспособления всей биопсихосоциальной системы к условиям биотехносоциума. Адаптация есть некое диалектическое единство согласования биопсихосоциальной системы с биотехносоциумом и их рассогласованности как особой формы динамического равновесия.

Важным процессом в устойчивости человека является проявление волевого акта в виде выносливости, поддерживаемого процессом адаптации. Выносливость нами определяется как противостояние воли человека утомлению и истощению его биопсихосоциальной системы на определенном отрезке времени в процессе достижения поставленной цели. Чем выше выносливость, тем устойчивее человек к разрушителям биотехносоциума при внутренних и внешних нагрузках. Следовательно, выносливость носит скорее динамичный, чем статичный характер и представляет собой активность, а не пассивность человека в процессе достижения поставленной цели.

Выносливость завершается процессом разрешения и носит позитивный оттенок, когда цель достигнута, и негативный оттенок, когда цель не достигнута. Разрешение наступает в любом случае после окончания выполнения определенного труда и сопровождается оцениванием результатов выполненных действий, осмыслением проделанного труда, формированием новой цели.

Устойчивость человека, как состояние, характеризуется: готовностью, активностью, удовлетворённостью и покоем. Эти состояния изменчивы и в большинстве случаев плавно перетекают друг в друга, сохраняя на максимально возможном уровне способность человека к действию. Поэтому они являются важнейшим аспектом устойчивости, играющие существенную роль в жизнедеятельности человека.
Под состоянием готовности следует понимать мобилизацию биопсихосоциальной системы человека на определенное действие для достижения поставленной цели и вариативность последствий. Готовность, как состояние устойчивости человека, имеет несколько смысловых оттенков: вооруженность необходимыми знаниями, умениями, навыками; возможность реализации имеющейся программы действия в ответ на появление определенного сигнала; согласие на решимость совершить какое-то действие. Состояние готовности соотносится с процессами целеполагания, принятием решения и адаптацией.

За готовностью следует состояние активности - это выполнение определенных действий для достижения поставленной цели. Поэтому активность, как состояние устойчивости человека, заключается в способности человека вступать во взаимодействие с биотехносоциумом, результатом которого являются конкретные действия. Состояние активности соотносится с процессом выносливости.

Активность, через некоторое время, сменяется состоянием удовлетворенности на фоне оценки результата проделанного труда. Удовлетворенность является субъективной оценкой качества тех или иных объектов, условий жизни и деятельности, жизни в целом, отношений с людьми, самих людей, в том числе и самого себя (самооценка). Устойчивость, как состояние удовлетворённости, отражает не отрицательное отношение человека к проделанной деятельности. Вслед за состоянием удовлетворённости наступает состояние покоя.

Устойчивость, как состояние покоя, заключается в относительном не реагировании на происходящие вокруг события. Это способность человека не вступать в активное взаимодействие с биотехносоциумом. Результатом такого состояния является равновесие всей биопсихосоциальной системы человека, его внутренняя умиротворённость, даже если она наступила в результате истощения.

Устойчивость человека, как свойство, определяется: аккумулированием, избирательностью, пластичностью, изменчивостью, уравновешенностью и сопротивляемостью. Под аккумулированием предлагается понимать накопление биопсихосоциальной системой человека поступающей информации из биотехносоциума. Цель накопления - последующее ее использование для сохранения устойчивости при движении к поставленной цели. Данное свойство выполняет информационное резервирование информации.

Избирательность - это отбор биопсихосоциальной системой человека полезной информации из всей совокупности поступающих сигналов из биотехносоциума. 
Избирательность позволяет человеку самостоятельно интерпретировать имеющуюся информацию, выбирать нужную в конкретной ситуации, что обеспечивает соответствующее реагирование.

Пластичность помогает биопсихосоциальной системе человека осуществлять приспособление при контакте с биотехносоциумом. Пластичность как свойство устойчивости раскрывает человека не только как податливого воздействиям, но и определённым образом как инертного или сопротивляющегося им.

Под изменчивостью следует понимать способность биопсихосоциальной системы человека изменяться под воздействием биотехносоциума. Когда начинают обнаруживаться признаки изменяющегося характера, но господствуют ещё старые. Зачастую изменение происходит непрерывно, бесконечно малыми шагами, что делает процесс изменения менее заметным.

Уравновешенность, как свойство устойчивости проявляется в способности биопсихосоциальной системы человека минимизировать негативное влияние биотехносоциума путем избегания крайностей в реакции на воздействующее событие.

Сопротивляемость, как свойство устойчивости обеспечивает способность биопсихосоциальной системы человека к сопротивлению разрушителям биотехносоциума, в способности переносить трудные ситуации без дезорганизации поведения.
Каждый представленный критерий возможно оценить, используя уже апробированные методы исследования, отраженные, к примеру в работах Campbell-Sills L. и Stein M.B. [7], Ralph L [8] и Sixbey M.T. [9].

Динамичность функциональной модели представленной на рис. 1, с учетом изложенного материала, можно проиллюстрировать рисунком 2.

Кривая Гаусса изображает вхождение человека в ситуацию (поле 1), присутствие в ней (поле 2) и выход из неё (поле 3) во временном интервале. Каждая ось X показывает непосредственное явление, происходящее в ситуации в конкретный промежуток времени в зависимости от поля. Ось Ү предназначена для фиксации маркеров, отражающих процессы в биопсихосоциальной системе устойчивости человека в конкретной временной точке по оси X любого поля. Таким образом, ситуация является единицей анализа устойчивости. Следует отметить, что высота кривой Гаусса для каждого конкретного человека своя. Но, в процессе отладки слаженной работы в коллективе воспитатель стремится к её усреднению. Особенное это касается профессий, связанных с деятельностью групп в сложных ситуациях (пожарные, спасатели, военные, полицейские и т.д.).

Исходя из функциональной модели устойчивости человека (рис 1.), с учетом понимания явлений, происходящих в нём, мы рекомендуем следующее. Исследовать, формировать и развивать устойчивость человека надо с

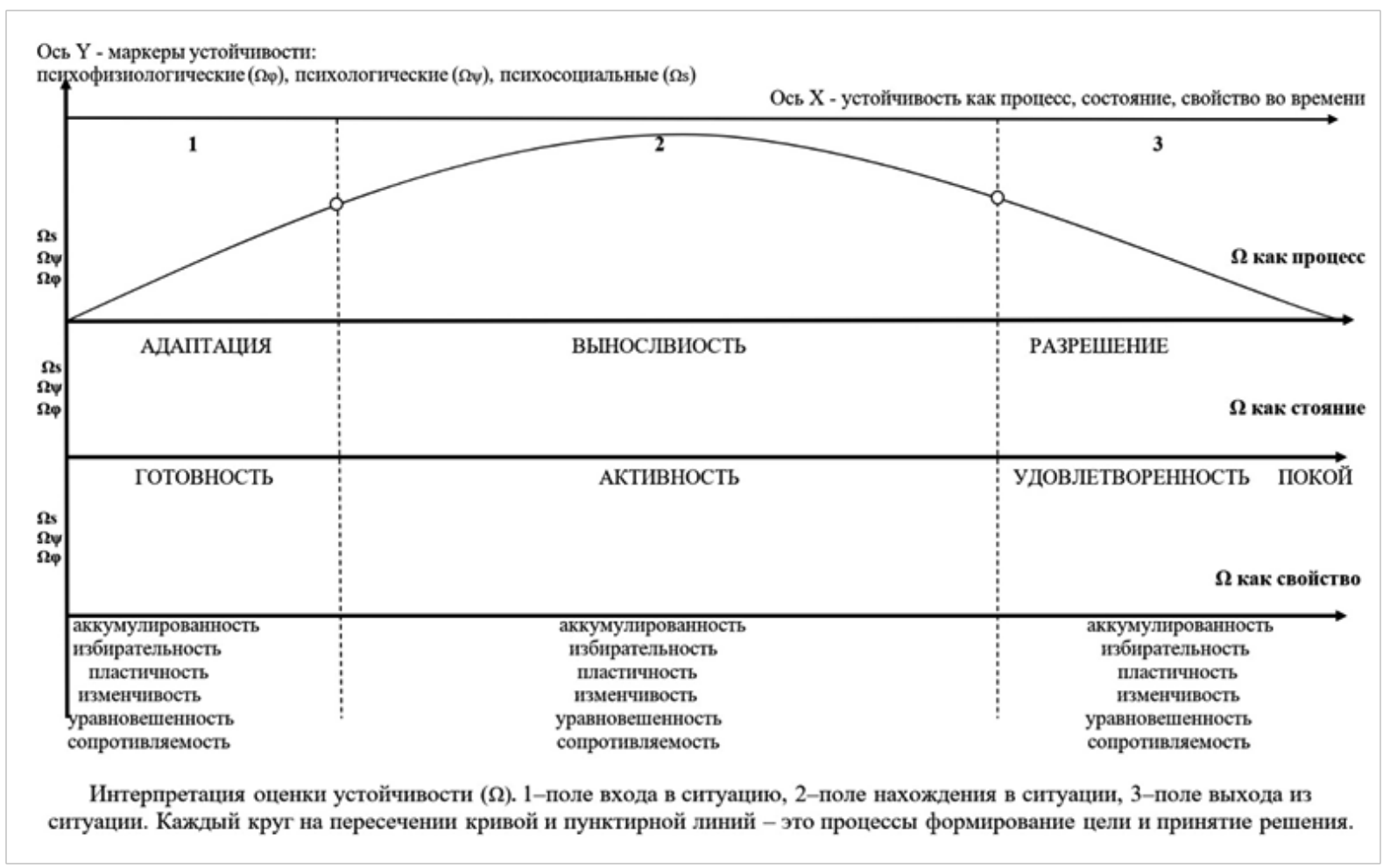

Рис. 2. Динамика функциональной модели устойчивости человека. 
учетом привязки к его жизнедеятельности. Предлагаем кратко рассмотреть матрицу стратегии исследования, формирования и развития устойчивости человека, используя Z-образный алгоритм (табл.1, рис. 3). За единицу анализа необходимо брать конкретные задачу и ситуацию.

Таблица1.

\begin{tabular}{|c|cc|cr|}
\hline ЗАДАЧИ & \multicolumn{2}{|c|}{ СИТУАЦИИДАРТНЫЕ } & \multicolumn{2}{|c|}{ НЕСТАНДАРТНЫЕ } \\
\hline ТИПОВЫЕ & $\Omega 1$ & TС & \\
\hline НЕТИПОВЫЕ & $\Omega 3$ & HС & TH & $\Omega 2$ \\
\hline
\end{tabular}

В первом сегменте матрицы ситуации не представляют собой опасности для потери устойчивости человеком: задачи типовые, ситуации стандартные. Данный сегмент характеризует «серые» будни человека. Они не чем не примечательны. Человек устойчив и находится в зоне комфорта.

Второй сегмент уже выводит человека из зоны комфорта. Возникает одна и более неизвестных переменных со стороны ситуаций, способных влиять на отклонение в устойчивости человека, вызывая некое напряжение и стресс. Человек вне зоны комфорта потеря устойчивости маловероятна так как решается типовая задача, отработанная до автоматизма. Но, тем не менее потеря устойчивости возможна из-за вероятности продолжительности воздействия разрушителей нестандартной задачи.

Третий сегмент матрицы является аналогом второго, только с другой переменной, другими переживаниями и стрессами. Во втором и третьем сегменте у человека начинает развиваться способность вариативного предвидения.
Четвёртый сегмент матрицы самый сложный и непредсказуемый. Экзамен на срезе ситуации между быть или не быть. Ячейка рождения героя, чемпиона, победителя. Данный сегмент меняет качество устойчивости человека, подобно изделиям из металла или стекла, прошедшим огненную закалку, чтобы обрести идеальную форму.

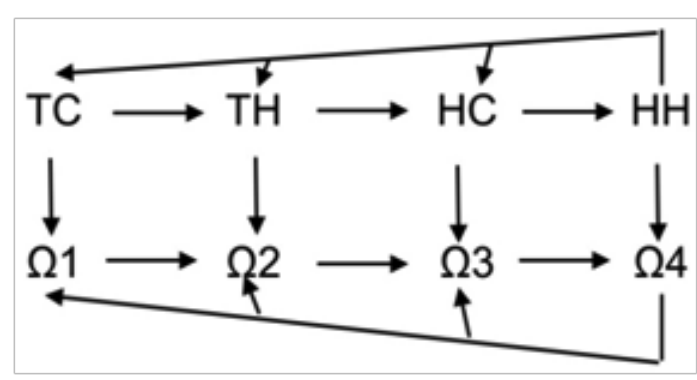

Рис. 3. Механизм алгоритма исследования и формирования устойчивости человека.

Из рис. 3 следует, что четвертый сектор матрицы становится первым на новом витке исследования, формирования и развития устойчивости человека.

В заключении отметим, что функциональная модель является одним из научных результатов диссертационного исследования автора статьи. В функциональной модели устойчивости человека устойчивость рассматривается как процесс, состояние и свойство. Устойчивость человека как процесс есть формирование цели, принятие решения, адаптация, выносливость и разрешение. Устойчивость человека как состояние есть готовность, активность, удовлетворенность и покой. Устойчивость человека как свойство есть аккумулирование, избирательность, пластичность, изменчивость, уравновешенность и сопротивляемость.

\section{ЛИТЕРАТУРА}

1. Казанков В. Психология устойчивости / Вячеслав Казанков. - [б. м.]: Издательские решения, 2019. - 324 с.

2. E. Seville. Resilience: Great Concept but What Does it Mean? // Compete Briefing Bite - Paper Presented at the US Council on Competitiveness Workshop, Risk and Resilience. Wilmington, USA. November 2008 • January, 2009.

3. Taleb N. Antifragile: things that gain from disorder. New York: Random House. 2012.

4. Крупник Е.П., Кисельникова Н.В. Психологическая устойчивость личности в трудных жизненных ситуациях. Монография. - М.: НОУ ВПО «МПСУ», 2014. $256 \mathrm{c}$.

5. Человек в современном мире: кризис и глобализация. Международная междисциплинарная коллективная монография / Сoct., peд. M. Le Chanceaux, И.Э. Соколовская - М.: Энциклопедист-Максимум, $2020-668$ с.

6. Большой психологический словарь / Сост. и общ. ред. Б. Г. Мещерякова, В.П. Зинченко. — СПб: Прайм-ЕВРОЗНАК, 2007. — 672 с.

7. L. Campbell-Sills, M.B. Stein. Psychometric analysis and refinement of the connor-davidson resilience scale (CD-RISC): validation of a 10-item measure of resilience J Trauma Stress, 20 (6) (2007), pp. 1019-1028

8. Ralph L Piedmont. Sixteen Personality Factor Questionnaire In book: Corsini Encyclopedia of Psychology // Chapter • January 2010 with 8,821

9. M.T. Sixbey. Development of the family resilience assessment scale to identify family resilience constructs. University of Florida (2005)

( Казанков Вячеслав Владимирович (legionfirst@mail.ru).

Журнал «Современная наука: актуальные проблемы теории и практики» 